\title{
"Shaping" population health: a challenge for public health
}

\author{
Dr. Panico is head of the Clinical Epidemiology Unit of the Dipartimento di Medicina Clinica e Sperimentale \\ at the Federico II University of Naples
}

Obesity is a global epidemic (WHO 1997). These few simple words summarize both the evidence derived from descriptive epidemiology and what people living and travelling across the world are familial with. High prevalence rates of obesity (and overweight) are detectable in the urbanized population of economically developed countries, as well as in wealthy subgroups of developing countries and in the socially disadvantaged groups in developed countries. It is easy to agree on that if obesity were an infectious disease an international emergency would have been declared. This issue of the journal proposes to the readers a number of papers which contribute to reaffirm this public health emergency. In Europe the battle against the health consequences of obesity is a high priority public health issue. The facts are that diseases with the major social impact such as cancer and cardiovascular disease are associated to excess weight. The proportion of all cancers attributable to excess weight in the European Union is $7 \%$ for women and $4 \%$ for men, with proportions up to more than $10 \%$ for some site-specific cancers (such as postmenopausal breast and colon). The figures are slightly higher for cardiovascular disease considering the metabolic and vascular effect of obesity.

In Europe as well as in North America some traits appear to be more worrisome than others.

Both cross-and within-country comparisons indicate that the social disadvantage of being less educated and poorer is associated with cheap and nutritionally deleterious dietary habits with the result that these social groups tend to take over the unfortunate supremacy for obesity. The gap in disease-free life span and good quality of life between upper and lower social classes is widening.

Childhood has increasingly become the starting age of nutrition related diseases like diabetes, hyperlipidemia, hypertension conducive to early cardiovascular disease. The American Heart Association has recently proposed a position statement to contrast this phenomenon (2003); action by
European scientific societies is urgently needed. This is because the very young generations are more obese than ever in the past and the future trends appear to be dramatically unfavourable if no public health action is readily taken. Many decades of epidemiological studies have provided sound information on the aetiological role of lifestyle on chronic disease and cancer, however those recognized protective habits associated to diet and physical activity are more and more abandoned. The result is that the potential advantages gained in knowing the population aetiology of chronic disease is being over-balanced by the disadvantages of the risk attributable to obesity in determining chronic disease and cancer. This phenomenon is striking in the European Mediterranean countries, where cardiovascular and cancer risk is approaching that of other European countries (BeerBorst et al. 2000; Haftenberger et al. 2002). The pathway traced by the growing rates of obesity in populations starts with the increasing prevalence of abdominal adiposity, glucose (insulin resistance, abnormal glucose tolerance and diabetes) and lipid metabolism (hypercholesterolemia, hypertrigliceridemia) disorders and hypertension. Cardiovascular disease incidence and mortality may increase as a result of these changes and becomes the sentinel for the forthcoming increase in cancer rates (WHO-IARC 2002). This is the case for the Mediterranean populations and a number of social groups in developing countries: a sort of economic development paradox.

Our communities should invest financial and human resources in planning and performing dietary intervention and physical activity promotion at population level. There is increasing evidence that health education approaches in young generations, which integrate social agencies (such as schools) with the family, may succeed (NHS-CRD 2002). However, the battle is very tough and is likely to be lost unless public health action is taken which involves the media and food production system. We know that food industry

Soz.- Präventivmed. 48 (2003) 141-142 
promotes high caloric density products (food and beverages) and that these are well backed by the advertisement system in young generations. The consumption of these products have been shown to be associated to the increased prevalence of overweight and obesity both in Europe and North America, especially among adolescents (Matthiesen et al. 2003; French et al. 2001). Awareness of this social condition is growing (Fried \& Nestle 2002), but still has not reached a critical mass to produce a new alliance among societal forces, including food industry, to reverse these features. Finally, we are aware that the lack of the positive image of the physically active youth in our societies leads to increase obesity rates over and above bad dietary habits (Troiano et al. 2000). Currently, the European Union is widening its boundaries. Many populations are sharing the dream of a new way of life. The challenge is not only on the economic side, but also (and mostly) on the quality of life. The global European society of the future is expected to be healthy in all its social sectors.

Salvatore Panico

\section{References}

AHA (2003). "Obesity, insulin resistance, diabetes and cardiovascular risk in children", American Heart Association Position Statement, presented at the 43th AHA meeting, Miami, USA, March 2003, in press on Circulation.

Beer-Borst S, Morabia A, Hercberg S, et al. (2000). Obesity and other health determinants across Europe: the EURALIM project. J Epidemiol Community Health 54: 424-30.

French SA, Story M, Neumark-Sztainer D, Fulkerson JA, Hannan P (2001). Fast food restaurant use among adolescents: associations with nutrient intake, food choices and behavioral and psychosocial variables. Int J Obes Relat Metab Disord 25: 1823-33.

Fried EJ, Nestle $M$ (2002). The growing political movement against soft drinks in schools. JAMA 288: 2181 .
Haftenberger M, Lahmann PH, Panico S, et al. (2002). Overweight, obesity and fat distribution in 50- to 64-year-old participants in the European Prospective Investigation into Cancer and Nutrition (EPIC). Public Health Nutr 5: 1147-62.

Matthiessen J, Fagt S, Biltoft-Jensen A, Beck AM, Ovesen L (2003). Size makes a difference. Public Health Nutr 6: 65-72.

NHS-Centre for Reviews and Dissemination (2002). Prevention and treatment of obesity in infancy. Effective Health Care 7(6): 1-12.

Troiano RP, Briefel RR, Carroll MD, Bialostosky $K(2000)$. Energy and fat intakes of children and adolescents in the United States: data from the National Health and Nutrition Examination Surveys. Am J Clin Nutr 72 (5 Suppl): 1343S-1353S.
WHO (1997). Obesity, preventing and managing the global epidemic: report of the WHO consultation of obesity. Geneva: World Health Organization.

WHO-IARC (2002). Handbook of cancer prevention: weight control and physical activity. Lyon: IARC Press.

\section{Address for correspondence \\ Prof. Dr. Salvatore Panico Dip. di Medicina Clinica e Sperimentale Università Federico II \\ Via Pansini, 5 \\ I-80131 Napoli \\ e-mail: spanico@unina.it}

